\title{
Comparison of commercially available food decontaminants with established methods of decontamination for household practices which are used to keep foods safe
}

\author{
*Feroz, F., Das, K.K. and Islam, T. \\ Department of Microbiology, Stamford University Bangladesh, 51 Siddeswari Road, Dhaka 1217, \\ Bangladesh
}

\section{Article history:}

Received: 17 April 2020

Received in revised form: 27

April 2020

Accepted: 2 May 2020

Available Online: 30 May

2020

Keywords:

Vegetables,

Foodborne illness,

Decontamination,

Vinegar

DOI:

https://doi.org/10.26656/fr.2017.4(5).175

\begin{abstract}
The microbiological safety of food has been a major concern in Bangladesh following several reports of food borne outbreaks associated with contaminated food and vegetables. To minimize the outbreak, several studies suggested that decontamination is necessary before cooking. Washing with water is the most common technique for decontamination in Bangladesh. In order to ensure food safety, the use of different food washing agents is also becoming popular day by day. For this reason, this study was conducted to evaluate the efficacy of various sanitizers and treatment method for decontamination. In this study, several decontamination methods including washing with hot water, cold water, salt water, vinegar and commercially available food sanitizer to evaluate for their efficacy against different microorganisms. Here, salad vegetables were washed with various sanitizers and then microbiological analysis was done to reveal the bacterial and fungal load. This study revealed that most of the sanitizing methods were able to reduce microbial load minimum by $2 \log \mathrm{CFU} / \mathrm{g}$. Vinegar and hot water wash were the most effective method of decontamination compare to others with the former showing a $3 \log \mathrm{CFU} / \mathrm{g}$ reduction. This can be concluded that common items like the use of vinegar and hot water were more effective than the commercial decontaminating agents available.
\end{abstract}

\section{Introduction}

Vegetables are an excellent source of nutrition and it serves as a favorite among many consumers (Nastou et al., 2012; Alam et al., 2015; Rahman et al., 2016). Additionally, many vegetables are available in the ready to eat format, such as salad or on its own as a snack. Leafy green vegetables and other ready to eat vegetables are a potential source of pathogens with the ability to cause food-borne illnesses, especially when consumed raw (Soriano et al., 2001; Ahmed et al., 2014; Alam et al., 2015; Rahman et al., 2016; Uhlig et al., 2017). Some vegetables are consumed after minimal processing in which the products are physically altered but they are still in their original state (Soriano et al., 2001; GomezLopez et al., 2008). This includes cutting, peeling, trimming and washing (Gomez-Lopez et al., 2008). Contamination may result from soil, water, manure, equipment, people and the quality of water used for cleaning (Gil et al., 2009; Alam et al., 2015; Rahman et al., 2016). Effective decontamination is of utmost importance in order to stop the spread of pathogens in the food cycle (Gil et al., 2009; Phua et al., 2014).
Decontamination methods such as irradiation, ultrasound and chemical sanitizers have recently received some negative reviews from its consumers, as recent revelations have highlighted the adverse effects of its use on both human health and the environment (Dionisio et al., 2009; Phua et al., 2014). Chemicals such as chlorine are already banned in many countries in Europe. Bacterial regrowth also serves as a problem, since many sanitizers lose its effect over time. According to The National Advisory Committee on Microbiological Criteria for Foods (NACMCF) foods should be subjected to a decontamination treatment, prior to consumption, which can effectively reduce the microbial presence by 5 $\log$ (Phua et al., 2014). Decontamination methods which can eliminate and reduce pathogens are required to maintain food safety, particularly if it is easy, cheap and reproducible (Olaimat et al., 2018).

Raw foods pose more of a threat as they are only subjected to washing and sanitizing methods used by individuals at home (Soriano et al., 2001; Nastou et al., 2014). Washing, with the use of water and other substances, is a form of decontamination which aims to 
remove dirt, residue, pesticide and microorganisms (Gil et al., 2009; Phua et al., 2014). Vinegar acid is a reduced form of acetic acid is known to be used in different households, against wounds and infections (Aspelund et al., 2016).

For this reason, the current study compared commercially available fruit and vegetable cleaners along with household products, which are commonly used for cleaning, such as hot water, cold water, salt water and vinegar wash in an attempt to identify which household remedies are as effective as or more effective than the cleaners.

\section{Materials and methods}

\subsection{Sample collection}

All samples were collected from local markets and brought to the laboratory as soon as possible. Fruit and vegetables cleaners and vinegar was purchased from supermarkets. A total of three salad vegetables including lettuce, cucumber and carrot (Lactuca sativa, Cucumis sativus and Daucus carota respectively) were used, collected from local markets of Dhaka city, Bangladesh within the time frame from September 2019 to October 2019. (APHA 1998; Noor et al., 2013; Hassan et al., 2013; Senjuti et al., 2014).

\subsection{Washing and sample processing}

Samples were treated with different washing agents and soaked for 30 mins. The washing agents included three different store-bought cleaners, hot water, cold water, $2 \% \mathrm{NaCl}$ water and vinegar water $(25 \%$ vinegar solution). All water used was boiled prior to use and allowed to cool at room temperature until the desired water temperature was achieved (Das et al., 2018).

\subsection{Enumeration of total viable bacteria (TVB), Total Fungi (TF), coliform and Staphylococcus spp.}

Raw and treated samples (10 g) were homogenized with $90 \mathrm{~mL}$ buffered peptone water (BPW). The homogenized samples were serially diluted up to $10^{-7}$ for microbiological analysis (Senjuti et al., 2014; Feroz et al., 2014; Mamun et al., 2016). In order to isolate total viable bacteria, total fungi, coliform and Staphylococcus spp., $0.1 \mathrm{ml}$ suspension of all 3 categories samples from $10^{-3}$ dilution was spread onto Nutrient Agar (NA), Sabouraud Dextrose Agar (SDA), MacConkey Agar and Mannitol salt agar (MSA) plates, respectively. All media Except Sabouroud Dextrose Agar (SDA) were incubated at $37^{\circ} \mathrm{C}$ for $24 \mathrm{hrs}$. and SDA was incubated at $25^{\circ} \mathrm{C}$ for 24 hrs. (Cappuccino and Sherman, 2001; Hassan et al., 2013; Feroz et al., 2014; Mamun et al., 2016).

\subsection{Observation of physical changes}

Along with the microbial analysis, physical changes were observed by soaking the whole vegetables in different washing agents for 30 mins.

\section{Results}

Lettuce (Figure 1) was highly contaminated with total viable bacterial growth of $\log 6.74 \mathrm{CFU} / \mathrm{g}$. Most of the decontaminating method able to reduce 2 to $3 \log$ reductions, while washing with vinegar showed a 4-log reduction in TVB (total viable bacteria). Here, vinegar also exhibited the highest reduction in the case of coliform and Staphylococcus spp. growth. All methods of washing were effective against fungal growth.

(A)

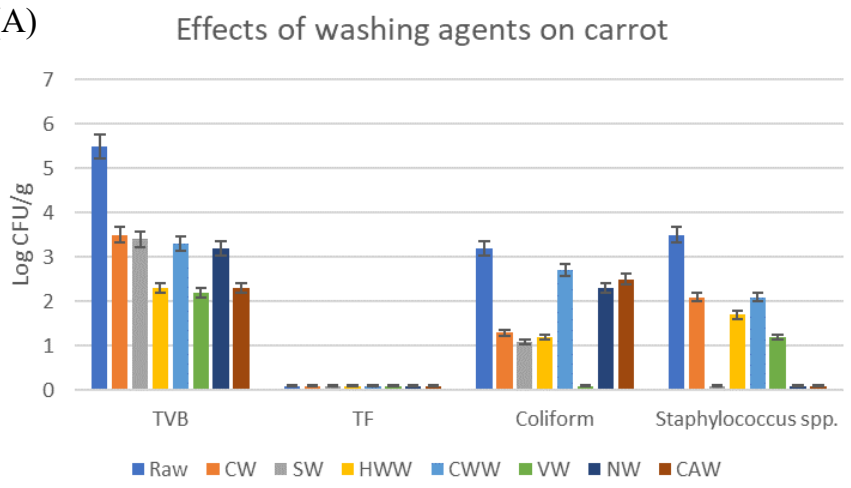

(B) Effects of washing agents on cucumber

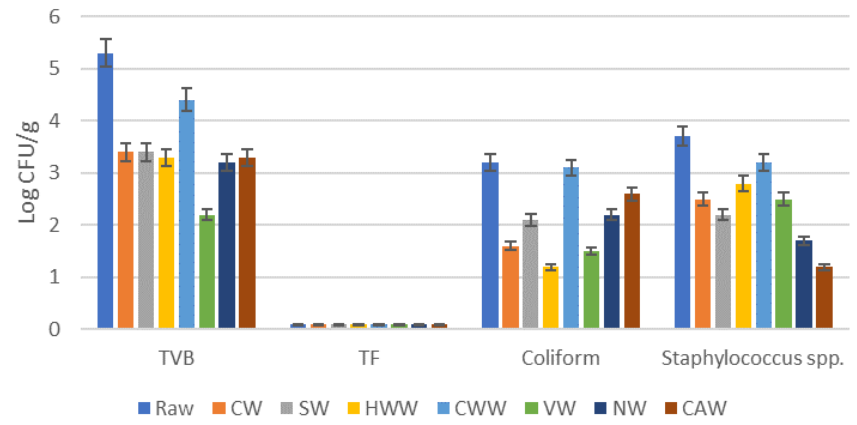

(C)

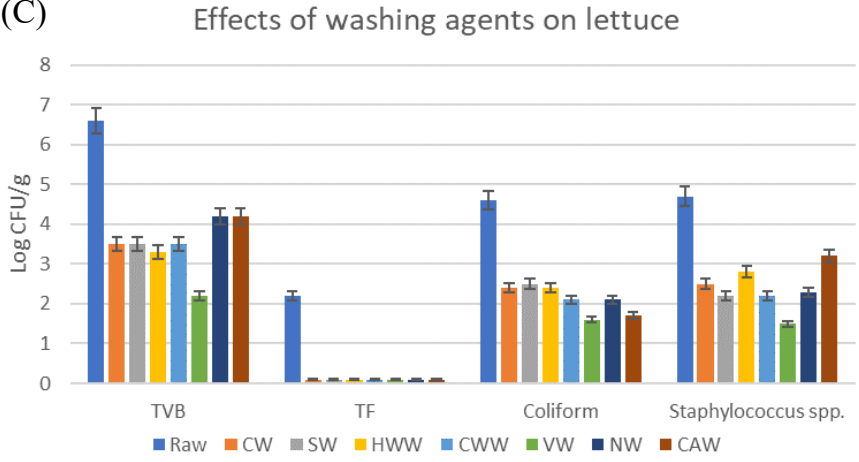

Figure 1. Log reduction of microbial population by commercially available sanitizers along with some common household methods of decontamination on (A) carrot, (B) cucumber and (C) lettuce. CW- Cleaning Agent 1, SWCleaning Agent 2, HWW- Hot Water Washed, CWW- Cold Water Washed, VW- Vinegar Washed, NW- $\mathrm{NaCl}$ washed, CAW- Cleaning Agent 3 
As seen in Figure 1, raw cucumber was contaminated with total viable bacterial growth of $\log$ $5.43 \mathrm{CFU} / \mathrm{g}$. Hot water and $\mathrm{NaCl}$ washing demonstrated a 2-log reduction while washing with vinegar showed a 3 $-\log$ reduction in TVB (total viable bacteria). Hot water washed showed the highest reduction in the case of coliform, while in case of Staphylococcus spp. cleaning agent 3 was most effective (2-log reduction). No fungal growth was observed.

According to Figure 1, carrot was highly contaminated with total viable bacterial growth of $\log$ $5.65 \mathrm{CFU} / \mathrm{g}$. Hot water was found to be most effective to reduced TVB (total viable bacteria) on carrots. Vinegar was able to completely eliminate coliform growth, then at the same time $\mathrm{NaCl}$ wash and cleaning agent 3 was most effective against Staphylococcus spp. growth. No fungal growth was observed.

\section{Discussion}

Salad vegetables, such as lettuce, cucumber and carrot are an important part of the human diet as well as a convenient source of nutrition (Uhlig et al., 2017). That said, they are also the carriers of different pathogens which can contribute to food-borne illnesses, especially when they are consumed raw (Gómez-López et al., 2008; Feroz et al., 2016). Therefore, in order to continue to enjoy the benefits of these ready to eat foods, proper cleaning and washing need to be ensured (Nastou et al., 2012). Methods that have been proven to be highly effective often use chemicals or radiation, both of which have become unfavourable due to changes observed in the food appearance and taste as well as due to the linkage of these methods with harmful side effects (Feroz, Mori and Sakagami, 2016). The current study analysed household cleaning methods and commercially available cleaners to assess their efficacy against pathogens that can cause illness in humans.

Studies carried out by Uhlig et al. (2017) on washing lettuce have shown that it was effective in reducing bacteria, similarly current study also revealed a decrease in bacterial growth on lettuce after washing. 3-log reductions were observed for both washing with cold and hot water. Uhlig also concluded that repeated washing with high water flow rate would produce even a greater reduction in growth. Studies conducted by Phua et al. (2014) compared chemical sanitizers with water-based methods. Their findings were partly in agreement with the current study, as the natural methods are more effective than chemical sanitizers and cleaning agents purchased from the store. Conversely, they identified hot water as the most effective, whereas our study found the vinegar and water mixture to be more effective among the natural methods (Table 1). It is to be noted that Phua et al. (2014) did not test vinegar-based solutions. Further analysis is required to properly identify one method as the most reliable.

Several studies on the effect of water washing at different temperatures were carried out, while some have found it effective others such as Nastou et al. (2012) have stated the decrease in growth is insignificant. To the best of knowledge, no study had carried out a comparison of cleaning agents with water and vinegarbased treatments. The current study found vinegar to be more effective among the household methods, in reducing bacterial growth than the other tested methods. The mixture of vinegar and water, as well as the salt and water, was able to produce the highest reduction of bacterial growth. Additionally, they both showed no physical change after use, whereas a texture change was observed after the use of hot water (Table 2). One important point to consider in sanitizing of foods is the quality of water used for washing (Gil et al., 2009). For this reason, the current study used boiled water which was cooled. To ensure the quality of water is always acceptable, use of boiled or filtered water is suggested. The cleaning agents showed similar results to that of vinegar wash, if not a higher reduction rate. The current study does not promote the use of this product as it is not a natural remedy and repeated use may become expensive.

A major difference between the current study and that of the two mentioned before was that this study attempted to use conditions that are observed in only one household. The vegetables were not inoculated prior to treatment and the raw counts were that of untreated vegetables, while the counts observed after treatment would be relatable to vegetables found in everyday

Table 1. Average reduction of microorganisms after using different cleanser on three categories of vegetables (log CFU/g)

\begin{tabular}{cccccccc}
\hline Microorganisms & CW & SW & HWW & CWW & VW & NW & CAW \\
\hline Total Viable Bacteria (TVB) & 2.3 & 2.3 & 2.9 & 2 & 3.6 & 2.2 & 2.5 \\
Total Fungi (TF) & 2.2 & 2.2 & 2.2 & 2.2 & 2.2 & 2.2 & 2 \\
Coliforms & 1.9 & 1.7 & 2 & 1 & 2.6 & 1.3 & 1.4 \\
Staphylococcus spp. & 1.6 & 2.5 & 1.5 & 1.3 & 2.2 & 2.6 & 2.5 \\
\hline
\end{tabular}

CW- Cleaning Agent 1, SW- Cleaning Agent 2, HWW- Hot Water Washed, CWW- Cold Water Washed, VW- Vinegar Washed, $\mathrm{NW}-\mathrm{NaCl}$ washed, $\mathrm{CAW}$ - Cleaning Agent 3 
household in Dhaka city. Therefore, the methods are not only easy to reproduce but they are applicable to natural conditions of foods in stores and in the houses. Additionally, the availability of sanitizers in Dhaka is limited, available only in select supermarkets. Also, the price of the sanitizer makes it too expensive for the majority of the country. Comparatively use of vinegar or water (hot/salt water) based methods are cheaper and easily can be conducted at home by anyone.

Table 2. Physical changes observed after exposure to washing agent

\begin{tabular}{cc}
\hline Washing agents & Physical changes observed \\
\hline CW & No Changes \\
SW & No Changes \\
HWW & Slight Change in texture \\
CWW & No Changes \\
VW & No Changes \\
NW & No Changes \\
CAW & No Changes
\end{tabular}

CW- Cleaning Agent 1, SW- Cleaning Agent 2, HWW- Hot Water Washed, CWW- Cold Water Washed, VW- Vinegar Washed, NW- $\mathrm{NaCl}$ washed, CAW- Cleaning Agent 3

\section{Conclusion}

Along with store-bought vegetable and fruit cleaners, hot water, cold water, salt water, and vinegar solution were tested, among them salt water and vinegar solution were the most effective in reducing bacterial and fungal load. Therefore, it is a viable alternative to the chemical sanitizers and other store-bought sanitizers available. These natural methods will not only remove dirt, pesticide and microorganisms it will also ensure no harmful side effects to the consumer. Vinegar and salt are also readily available in all stores with the prices range being affordable for most.

\section{Conflict of interest}

The authors declare no conflict of interest.

\section{Acknowledgments}

We thank Microbiology Laboratory, Stamford University Bangladesh for laboratory facilities, technical assistance and financial aid.

\section{References}

Ahmed, T., Baidya, S., Sharma, B.C., Malek, M., Das, K.K., Acharjee, M., Munshi, S.K. and Noor, R. (2013). Identification of drug-resistant bacteria among export quality shrimp samples in Bangladesh. Asian Journal of Microbiology, Biotechnology and Environmental Sciences, 15(4), 31-36.

Alam, M.S., Feroz, F., Rahman, H., Das, K.K. and Noor,
R. (2015). Microbiological contamination sources of freshly cultivated vegetables. Nutrition and Food Science, 45(4), 646 - 658. https://doi.org/10.1108/ NFS-04-2015-0032

APHA (American Public Health Association). (1998). Standard Methods for the Examination of Water and Wastewater. Washington, D.C., USA: American Public Health Association.

Aspelund, A.S., Sjöström, K., Liljequist, O., Mörgelin, A., Melander, E. and Pahlman, L.I. (2016). Acetic Acid as a decontamination method for sink drains in a nosocomial outbreak of metallo- $\beta$-lactamase producing Pseudomonas aeruginosa. Journal of Hospital Infections, 94(1), 13-20. https:// doi.org/10.1016/j.jhin.2016.05.009

Cappuccino, J.G. and Sherman, N. (2005). Microbiology: A laboratory manuals. $7^{\text {th }}$ ed. USA: Benjamin Cummings.

Das, A. K., Sultana, Z., Kabir, A. and Kabir, M. S. (2018). Effect of washing on reducing bacterial loads in common vegetables sold in Dhaka City. Bangladesh Journal of Microbiology, 35(2), 96-101. https://doi.org/10.3329/bjm.v35i2.42637

Dionisio, A.P., Gpmes, R.T. and Oetterer. (2009). Ionizing radiation effect on food vitamins: A review. Brazilian Archives of Biology and Technology, 55 (5), 1267-1278. https://doi.org/10.1590/S151689132009000500026

Feroz, F., Mori, M. and Sakagami, Y. (2016). Bacterial and Fungal loads in Raw Sea Foods, Fruits and Vegetables Collected from Dhaka Bangladesh and the Effect of Heat on Its Growth. Bangladesh Journal of Microbiology, 33(1-2), 23-28. https:// doi.org/10.3329/bjm.v33i1.39599

Feroz, F., Senjuti, J.D., Tahera, J., Das, K.K. and Noor, R. (2014). Investigation of microbiological spoilage and demonstration of the anti-bacterial activity of the major imported fruits within Dhaka Metropolis. Stamford Journal of Microbiology, 4(1), 1-4. https:// doi.org/10.3329/sjm.v4i1.22752

Feroz, F., Shimizu, H., Nishioka, T., Mori, M. and Sakagami, Y. (2016). Bacterial and Fungal Counts of Dried and Semi-Dried Foods Collected from Dhaka, Bangladesh, and Their Reduction Methods. Biocontrol Science, 21(4), 243-251. https:// doi.org/10.4265/bio.21.243

Gil, M.I., Selma, M.V., López-Gálvez, F. and Allende, A. (2009). Fresh-cut product sanitation and wash water disinfection: Problems and solutions. International Journal of Food Microbiology, 134(12), 37-45. https://doi.org/10.1016/ j.ijfoodmicro.2009.05.021 
Gómez-López, V.M., Ragaert, P., Debevere, J. and Devlieghere, F. (2008). Decontamination Methods to Prolong the Shelf-life of Minimally Processed Vegetables, State-of-the-art. Critical Reviews in Food Science and Nutrition, 48(6), 487-495. https:// doi.org/10.1080/10408390701638878

Hassan, M.R., Acharjee, M., Das, E., Das, K.K., Ahmed, T., Akond, M.A., Fatema, K.K. and Noor R. (2013). Microbiological study of sea fish samples collected from local markets in Dhaka city. International Food Research Journal, 20(3), 1491-1495.

Mamun, S.A., Das, K.K. and Uddin, M.A. (2016). Microbiological analysis and determination of antibacterial activity of apple samples collected from local markets in Dhaka city, Bangladesh. Stamford Journal of Microbiology, 6(1), 11-16. https:// doi.org/10.3329/sjm.v6i1.33511

Nastou, A., Rhoades, J., Smirniotis, P., Makri, I., Kontominas, M. and Likotrafiti, E. (2012). Efficacy of household washing treatments for the control of Listeria monocytogenes on salad vegetables. International Journal of Food Microbiology, 159, 247-253. https://doi.org/10.1016/ j.ijfoodmicro.2012.09.003

Noor, R., Acharjee, M., Ahmed, T., Das, K.K., Paul, L., Munshi, S.K., Urmi, N.J., Rahman, F. and Alam, M.J. (2013). Microbiological analysis of major sea fish collected from local markets in Dhaka city, Bangladesh. The Journal of Microbiology, Biotechnology and Food Sciences, 2(4), 2420-2430.

Olaimat, A.N., Al-Holy, M.A., Shahbaz, H.M., AlNabulsi, A.A., Abu Ghoush, M.H., Osaili, T.M., Ayyash M.M. and Holley, R.A. (2018). Emergence of antibiotic resistance in Listeria monocytogenes isolated from food products: a comprehensive review. Comprehensive Reviews in Food Science and Food Safety, 17(5), 1277-1292. https:// doi.org/10.1111/1541-4337.12387

Phua, L.K., Neo, S.Y., Khoo, G.H. and Yuk, H. (2014). Comparison of the efficacy of various sanitizers and hot water treatment in inactivating inoculated foodborne pathogens and natural microflora on mung bean sprouts. Food Control, 42, 270-276. https://doi.org/10.1016/j.foodcont.2014.02.013

Rahman, H., Feroz, F., Alam, M.S., Das, K.K. and Noor R. (2016). Demonstration of the source of microbial contamination of freshly cultivated cabbage, cauliflower, potato and squash collected from rural farms of Bangladesh. International Food Research Journal, 23(3), 1289-1295.

Senjuti, J.D., Feroz, F., Tahera, J., Das, K.K. and Noor, R. (2014). Assessment of microbiological contamination and the in vitro demonstration of the anti-bacterial traits of the commonly available local fruit blend within Dhaka Metropolis. Journal of Pharmacognosy and Phytochemistry, 3(1), 73-77.

Soriano, J.M., Rico, H., Molto, J.C. and Ma, J. (2001). Incidence of microbial flora in lettuce, meat and Spanish potato omelette from restaurant. Food Microbiology, 18(2), 159-163. https:// doi.org/10.1006/fmic.2000.0386

Uhlig, E., Olsson, C., He, J., Stark, T., Sadowska, Z., Molin, G., Ahrné, S., Alsanius, B. and Håkansson, Å. (2017). Effects of household washing on bacterial load and removal of Escherichia coli from lettuce and "ready-to-eat" salads. Food Science and Nutrition, 5(6), 1215-1220. https://doi.org/10.1002/ fsn 3.514 